\title{
绿色基础设施视角下城市河道生态修复理论与实践 以西雅图为例
}

Theories and Practices of Urban River Restoration in the Perspective of Green Infrastructure: The Case of Seattle

摘要：城市化导致城市河道渠化和生态退化。通过生态修复重建城市 河道的自然动态过程, 有助于提升河道生态系统功能, 促进城市流域 健康。本文概述城市河道修复的内涵和方法; 以西雅图市河道修复项 目为例, 阐述修复设计与城市功能、雨洪管理整合的方法和过程, 并 评估其结果和价值。研究表明: 河道修复是促进西雅图重构城市流域 生态连接的重要手段, 以及未来绿色基础设施网络规划的关键廊道和 节点; 在建成环境的限制下, 西雅图发展了局部渐进的修复策略, 为 城市可持续开发、社区复兴提供了良好契机; 各利益群体的参与和协 作是实践得以推进的保障; 评价应基于多元目标及价值。这些经验可 为中国 “城市双修”工作提供具体思路, 促进城市可持续转型。

Abstract: Urbanization leads to canalization and ecosystem degradation of urban rivers. Ecological restoration would reestablish urban river dynamics, thus improve river ecosystem function and urban watershed health. This paper summarizes the definition and methods of urban river restoration. Through case study of several restoration projects in Seattle, it explores the integration of the restoration design with urban functions and stormwater management and assessed their outcomes and values. Some findings are highlighted. River restorations promote urban watershed connectivity and work as potential links and nodes of the green infrastructure network. The small cumulative restorations under urban constraints provide opportunities for urban sustainable development and community revitalization. Stakeholder's participation and collaboration are key to the advance of restoration. Assessing restoration should consider multiple objectives and values. These lessons are valuable to the current ecological restoration and urban enhancement projects in China, promoting sustainable urban transformation.

关键词: 河道修复; 绿色基础设施; 城市流域; 生态系统; 社会效益 Keywords: River Restoration; Green Infrastructure; Urban Watershed; Ecosystem; Social Benefits

国家自然科学基金项目 (41501169), 国家建设高水平大学公派研究生项 目 (201506250028)

作者: 李雅, 天津大学建筑学院博士研究生; 华盛顿大学景观建筑系联合 培养博士研究生。liya@tju.edu.cn

\section{引言}

城市化是威胁河道健康和完整性的主要因素, 其严重 导致河道生态系统的结构和功能退化, 使城市人口受到水 安全问题（如洪灾、水质污染等）和栖息地退化的高度威 胁, 并且影响河道为城市人口提供相关的利益 ${ }^{[1,2]}$ 。河道受 流域城市化的影响被称为 “城市河流综合征” (urban stream syndrome), 表现为洪峰流量大且快速、河床侵蚀和退化、 养分和污染物含量高、生物多样性降低等 ${ }^{[3]}$ 。其主要驱动因 素是城市不透水表面产生的雨水径流直接排人河道, 其他还 包括合流制溢流 (CSO : Combined Sewer Overflow)、污水 处理厂排放等 ${ }^{[3]}$ 。为了在城市中稳固河道, 通常对河道实施 河道整治工程 (如渠化、取直、遮盖或掩埋等), 以满足泄洪、 排涝或通航的需求, 并最大化沿岸城市开发。对河岸、泛洪 区栖息地的挤占导致河道丧失雨洪滞蓄和自我迁移的空间, 河道疏浚清淤使河床形态及栖息地均质化 ${ }^{[4]}$ 。

河道生态修复能够帮助减缓流域退化, 并提升河道健康 及其生态系统服务, 这促使城市河道管理的范式从传统水利 工程向绿色基础设施转变 ${ }^{[4,5]}$ 。这种转变一方面由于整合了 生态过程, 可实现河道的多功能性和适应性; 另一方面促进 构建城市的绿色空间网络, 保护生态的同时为人类提供相关 利益 ${ }^{[6]}$, 从而提高了城市的可持续性和应对变化的韧性。因 此, 绿色基础设施的视角为城市河道修复提供了一个整合生 态和城市的框架 : 城市河道修复自身构成绿色基础设施网络 的连接廊道和节点, 并促进其他绿色基础设施系统的建立, 使该网络不断完善; 同时, 城市河道修复将社区居民、社会 组织及活动、项目实践连接到绿色基础设施网络, 形成与其 密切相关的社会网络和可持续城市开发。

由于快速和大规模的城市化, 我国城市河道及流域的退 化更为严重 ${ }^{[7]}$ 。2017 年 3 月, 住建部正式提出《关于加强生 
态修复、城市修补 (简称 “城市双修”) 工作的指导意见》, 其中对开展水体治理和修复加以强调, 为发展适合我国的城 市河道修复理论和实践提供了良好机遇。在北美和欧洲已有 大量有关河道修复的研究和实践, 但城市河道修复仅占很小 的比例 ${ }^{[8]}$ 。在城市中修复河道所面临的实际挑战包括 : 在人 工化的生态系统和局限的建成环境下恢复河道的自然动力过 程, 是否值得修复, 以及如何修复。为回答这个问题, 本文 在强调城市河道特殊性的基础上, 总结城市河道修复的内涵 和方法; 并以美国西雅图的修复实践为例, 阐述城市河道修 复与场地文脉、城市功能相整合的方法和过程, 以及其作为 绿色基础设施为城市提供生态和社会文化的综合效益。希望 藉以此文为我国当下全面开展的 “城市双修” 工作提供具体 思路, 促进城市自然河道与人工建成环境二者的协同发展, 实现城市的可持续化转型。

\section{1 城市河道修复概述}

\section{1 城市河道修复的内涵}

国际生态修复协会 (Society for Ecological Restoration) 将 “生态修复” (ecological restoration) 定义为 : 帮助恢复已 受损、退化或破坏的生态系统的过程 ${ }^{[9]}$ 。河道本身作为生态 系统, 具有自我修复的能力; 河道生态修复是为其提供一个 自我修复的机会和环境, 促进并加速整个恢复过程 ${ }^{[10]}$ 。河道 生态修复的最终目标是恢复河道完整的生态过程和功能, 使 其回到一个接近于被干扰前的状态 ${ }^{[11]}$ 。修复评价注重河道的 生态属性, 通常以反映水质和生物状况的物理化学和生物参 数作为评价指标 ${ }^{[12]}$ 。但是城市河道 ${ }^{1}$ 不同于其他地区（如乡 村或自然区等) 的河道, 在修复目标、评价与策略等方面具 有一定的特殊性。

\section{1 .1 修复生态系统服务}

在城市中, 可用于河道修复的空间较为有限, 并且征地 难度大、成本高。这些挑战导致大部分的修复项目呈现小尺 度、片段化的空间特征, 修复场地通常由获取土地的机会决 定, 而不是基于生态价值最大化的考虑 ${ }^{[13]}$ 。对于生态严重退 化的城市河道及流域, 城市河道修复的生态价值较为有限, 而试图修复整个河道生态系统, 使其回到某个历史状态是难 以实现且没有必要的。城市河道修复的目标应强调修复特定 的生态系统功能和服务, 使其达到一个新的动态平衡 ${ }^{[14]}$ 。在 这个目标下, 城市河道修复是一个设计生态系统的过程, 其 通过修复河道关键的生态结构和过程, 提升相应的功能, 以 支撑并最大化预期的生态系统服务, 进而满足特定的经济社
会需求; 稳固河道、改善水质、增加栖息地和生物多样性是 城市河道修复最常见的三个需求 ${ }^{[12]}$ 。同时, 城市河道修复所 建立的是一个经过修正的或全新的生态系统, 融人所在场地 环境, 并沿着一个改变的生态轨迹再次演化和适应外界 ${ }^{[10,14]}$ 。

\section{1 .2 修复作为社会过程}

城市河道修复不仅是技术应用，更是一种社会过程 ; 相 比于有限的生态价值, 其最大效益是社会效益 ${ }^{[15,16]}$ 。一方面, 河道的生态系统服务为人类提供多种益处, 包括减少洪灾, 改善微气候、野生动物栖息地, 游敀娱乐, 学习教育和美学 价值等, 还会提高房地产价值 ${ }^{[17]}$ 。另一方面, 修复本质上被 认为是一种社会现象, 是由一系列社会决策过程支撑的 ${ }^{[15,18]}$, 包括相关的环境政策制定和立法、社会投资、目标制定以及 各利益群体参与协作等; 同时, 修复项目激发社区居民和社 会组织主动参与到决策、实施和管理当中, 形成自下而上的 关键力量, 在此过程中提高了社会的环境意识和凝聚力, 并 促进社区建设和复兴。因此, 城市河道修复需要在一个社会 经济的背景下考量, 修复评价也从单一的生态学指标向结合 人类需求和使用的包容性框架扩展。帕默等 (Palmer et al.) 认 为, 最成功的修复项目能够同时实现三个方面的目标, 即满 足利益相关者的需求、促进学习以及提升生态性能 (图 1) ${ }^{[19]}$ 。

\section{1 .3 修复基于双重尺度}

城市河道区别于其他河道的重要特征是流域城市化, 当 流域的不透水表面率超过 10\% 20\% 时，河道生态状况会发 生明显退化 ${ }^{[1]}$ 。这使得城市河道修复不能仅关注河道自身, 还需强调流域尺度。河段尺度的修复能够局部提升河岸植被 和河道栖息地, 使河道结构呈现更自然的状态, 同时在短 期内为城市人口提供一系列的社会效益。这种仅关注河道 自身的修复虽然十分必要, 但在城市环境下并不足够, 因

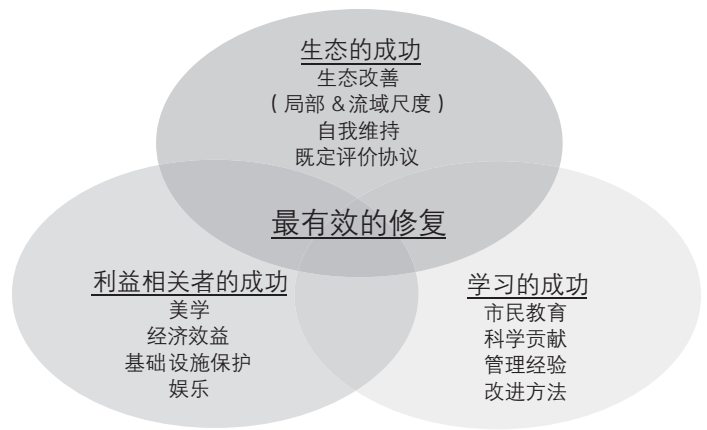

图 1 成功的城市河道修复项目定义 资料来源 : 参考文献 [19]

(1) 本文中城市河道是指流经城市的河流、运河、溪流、人工渠等。 
为大部分影响产生于河道之外的城市流域, 其不仅无法减 缓流域城市化的影响, 甚至还会限制自身的修复效果、损 坏修复工作 ${ }^{[20]}$ 。流域尺度的修复能够减缓雨水径流对河道 的影响, 帮助恢复河道的关键过程, 使河道系统更趋向于 自我维系并弹性应对外界干扰。在城市中实现长期、有效 的生态改善是 “需要用一个流域去修复一条河道” ${ }^{[21]}$, 但是 通常流域尺度的修复实践相对匮乏, 甚至被忽略。

\section{2 城市河道修复的方法}

\subsection{1 基于形式的方法}

当前, 城市河道修复广泛使用的方法是自然河道设计 (natural channel design), 这种方法更关注于河道形态及结 构的重建和设计, 而非受损生态过程的修复。提出者罗斯格

(Rosgen) 认为, 河道设计是为了使河道在当前受损的水文 地形过程中保持稳定性, 一旦河道能够应对这个过程, 则生 态过程会自然修复 ${ }^{[12]}$ 。其借助河道分类和形式模板确定稳定 的河道形式, 通过对河道外形及内部结构重建, 降低水流速 度、稳固河岸, 同时提高河道内栖息地复杂度 ${ }^{222]}$ 。具体措施 包括：安置河岸卵石及填料, 种植河岸植被, 河道再弯曲化 以及在河道内安置倒木和深潭浅滩结构等。很多研究表明, 大部分城市河道设计项目的生态状况并没有明显改善, 导致 这种方法受到学界越来越多的质疑和批判 ${ }^{[12]}$ 。但是, 这种方 法基于设计模式和标准、可参照设计手册, 具有较强的实践 性和操作性; 并且可使河道相对稳定、看起来更自然, 能够 快速将人工化河道提升为城市绿色空间, 提供多种社会效益, 因而成为城市河道修复的普遍方法。

\subsection{2 基于过程的方法}

生态连接是绿色基础设施的核心方法, 其使河道系统 的内部之间、系统与外部之间相互连通, 促进河道的自然动 态过程, 保证有机物、泥沙、营养物等运输和能量交换。修 复河道连接是修复生态过程的根本措施, 这种方法强调河道 受城市化制约的根源, 通过减缓或移除制约要素, 实现河 道生态过程和功能自我恢复。修复连接主要有以下措施 ${ }^{[4]}$ :

（1）修复流域连接。通过雨洪管理、林地恢复和污染源控 制, 降低河道洪峰和侵蚀, 并减少污染物含量; (2) 修复 河道上、下游连接 (即纵向连接)。通过移除河道涵洞或小 型水坝, 恢复鱼类洄游通道; (3) 修复河道与河岸、泛洪 平原连接 (即侧向连接)。通过移除河岸硬化、后退河堤和 恢复植被, 重建自然的河岸和泛洪平原, 进而恢复河道的侧 向迁移过程以及雨洪滞蓄、有机物保持等功能, 并增加栖息 地多样性。基于过程的方法需要建立在对河道系统的结构、 过程和功能之间关系的理解之上, 明确修复措施产生的系统
回应 ${ }^{[12]}$; 特别是对于城市中复杂而特定的场地条件, 通常需 要修复项目前、后的长期监测来获得。这种修复方法在学界 具有广泛的支撑, 但实施和监测尚处于起步阶段。

\section{2 西雅图的河道修复实践}

在美国《清洁水法》(Clean Water Act, 1972) 和《濒 危物种法》(Endangered Species Act, 1973) 的推动下, 西 雅图长期致力于普吉特海湾 (Puget Sound) 及相关水域的 水质改善和鲑鱼恢复。河道修复不仅为鲑鱼及其他野生动 物提供栖息地, 也在城市雨水径流进人河道、湖泊和海湾 前起到调蓄和过滤作用。西雅图实施长期、流域尺度的修 复和短期、河段尺度的修复相结合的策略, 既能逐步提升 流域健康和城市韧性, 又可快速改善河道, 提供环境和社 会初始效益（图 2)。

\section{1 流域尺度的修复实践}

西雅图是高度城市化地区, 受海洋性气候影响而降雨频 繁。西雅图由四个城市流域构成, 其中包括多个城市溪流流 域（图 3); 不透水表面占城市总面积约 $60 \%{ }^{|23|}$, 因而有大量 的雨水径流产生并进人城市河道。2014 年约有 130 亿加仑 (492 亿升) 的雨水径流和约 400 次、1.2 亿加仑（4.5 亿升) 的合流制溢流直接排人城市内及周边水体 ${ }^{[24]}$ 。

西雅图公共事业局（Seattle Public Utilities）因此实行了 “保护我们的水体” (Protect Our Waters) 计划, 为城市河道 修复制定了一个流域管理框架。该框架包括减缓雨水径流、 阻止污染物、修复植被及水生栖息地等三个方面内容及一系 列具体项目, 强调流域尺度的修复对保护和修复河道具有关 键作用（表 1 ${ }^{[25]}$ 。在这个计划中, 西雅图将绿色基础设施 作为河道流域修复的重要措施, 实施于城市溪流流域和混合 污水排水分区内, 帮助减缓雨水径流及合流制溢流冲刷和污 染河道。当前已完成的绿色基础设施可管理 1 亿加仑（3.8 亿升) 雨水径流, 西雅图设定的目标是至 2025 年实现管理

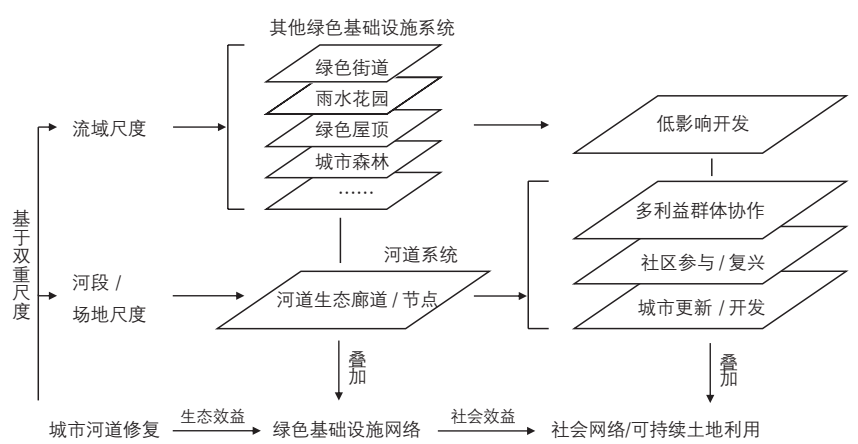

图 2 基于绿色基础设施的城市河道修复框架 资料来源 : 作者绘制 
7 亿加仑 (26.5 亿升) 雨水径流 ${ }^{[26]}$ 。为实现这个目标, 其不 仅在社区和街区的公共空间、路边实施绿色基础设施, 并在 私有权属地块上推行绿色基础设施, 鼓励居民 “在家中管理 雨水”。这个计划促进了绿色基础设施网络在城市不同尺度 的构建和完善。

\section{2 河段尺度的修复实践}

\subsection{1 城市河口栖息地修复}

杜瓦米许河 (Duwamish River) 下游位于西雅图南部工 业区, 是高度城市化河口, 初始形成于 20 世纪初的河道裁 弯取直工程。其作为西雅图港和沿河工业的运输航道, 支撑 着大量的就业和商贸活动, 是西雅图经济的重要构成。同时, 作为西雅图唯一的河流, 咸淡水混合的河口是鲑鱼重要的栖 息地, 然而原有的河口栖息地已基本消失, 且河道受到工业 废物和城市排水的严重污染。为了减缓影响, 自 1960 年代 开始杜瓦米许河致力于减少合流制溢流、防止和清理污染物 以及修复鲑鱼栖息地。2 001 年美国环境保护局仍将其列为 国家最严重的污染场地之一 ${ }^{[27]}$ 。

尽管在高度工业化的河口实施栖息地修复极具挑战性和 不确定性, 杜瓦米许河自 1988 年至今已完成了 19 个修复项 目, 并有 3 个正在设计和实施中。修复十分依赖在高度开发

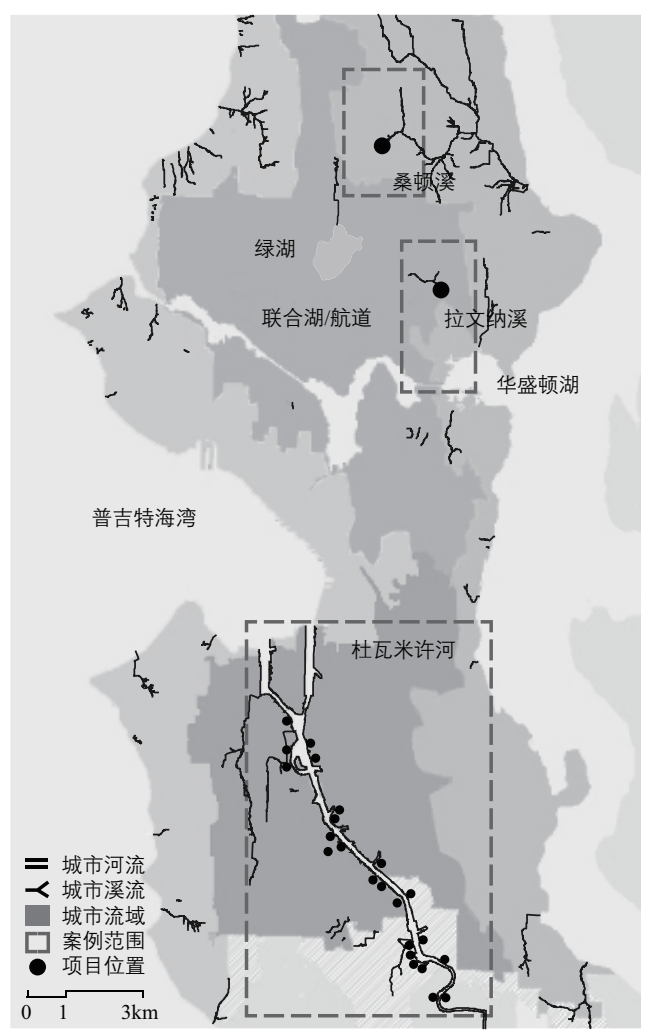

图 3 西雅图城市流域及河段尺度修复案例位置 资料来源 : 作者绘制
的河道两侧寻找获得土地的机会。因此, 杜瓦米许河道修复 使用的策略是小尺度渐进式修复 ${ }^{[28]}$ : 通过小的独立修复项目

(通常 $<1 \mathrm{hm}^{2}$ ) 逐渐积累, 形成景观尺度上的栖息地功能性 连接, 并且在局部聚集多个小项目构成较大的关键斑块, 从 而为鲑鱼等野生生物提供生态有效的栖息地（图 4a)。

杜瓦米许河道修复在长期的实践中不断改进, 修复设计 逐渐从关注形式到基于过程，并且从局限于场地本身到将场 地置于一个景观尺度下思考, 建立场地节点并与周边潜在绿 色网络整合。具体表现为三个特征明确的阶段 ${ }^{[28]}$ : (1) 初期 的生态补偿项目关注于河岸改善或栖息地要素的创造, 如移 除河岸硬化和人工结构、堆建土丘、种植河岸植被和增加浅 水滩等, 为鲑鱼和其他生物提供庇护所、食物等; (2) 此后 项目开始强调恢复场地的潮汐过程, 促进潮汐湿地的自我恢 复, 通过整理合适的潮间带高程和坡度, 恢复从泥滩、盐沼 到河岸植被的自然过渡带（图 4b）；(3）在一些有潜力的场 地, 修复项目试图合并既存的小项目, 或者扩展河道的泛洪 空间以及联通其他水系, 如开掘潮沟或潮汐池, 通过移除涵 洞重建与后置沼泽的连接, 甚至重建与整个溪流流域的连接 (图 4c)。同时, 杜瓦米许河道修复也从零散、基于机会的 实践向系统、整体规划的方向发展。2009 年西雅图港 (Port of Seattle) 制定了《杜瓦米许河下游栖息地修复计划》(Lower

表 1 西雅图 “保护我们的水体” 框架及修复项目

\begin{tabular}{|c|c|c|c|c|}
\hline 尺度 & 内容 & 主要修复项目 & 具体措施 & 实施效果 \\
\hline \multirow{5}{*}{$\begin{array}{l}\text { 流域 } \\
\text { 尺度 }\end{array}$} & \multirow{2}{*}{$\begin{array}{l}\text { 减缓 } \\
\text { 雨水 } \\
\text { 径流 }\end{array}$} & $\begin{array}{l}\text { 自然排水系统项目 } \\
\text { (Natural Drainage } \\
\text { System) }\end{array}$ & $\begin{array}{l}\text { 在城市溪流流域的街区 } \\
\text { 或社区实施路边绿色基 } \\
\text { 础设施 (生物滞留塘、 } \\
\text { 洼地、透水铺装等) }\end{array}$ & $\begin{array}{l}\text { 减少 } 74 \% \text { 99\% 雨 } \\
\text { 水径流排人城市溪 } \\
\text { 流; 减少 5\% 11\% } \\
\text { 不透水表面 }\end{array}$ \\
\hline & & $\begin{array}{l}\text { 雨水智慧项目 } \\
\text { (RainWise) }\end{array}$ & $\begin{array}{l}\text { 鼓励并补偿在私有地块 } \\
\text { 实施绿色基础设施（雨 } \\
\text { 水花园、雨水收集箱等） }\end{array}$ & - \\
\hline & \multirow[t]{2}{*}{$\begin{array}{l}\text { 阻止 } \\
\text { 污染 } \\
\text { 物 }\end{array}$} & $\begin{array}{l}\text { 合流制溢流削 } \\
\text { 减项 目 (CSOs } \\
\text { Reduction) }\end{array}$ & $\begin{array}{l}\text { 在混合污水排水区的街 } \\
\text { 区或社区实施路边绿色 } \\
\text { 基础设施; 修建大容量 } \\
\text { 地下存储水箱 ; 改善污 } \\
\text { 水处理设施 }\end{array}$ & $\begin{array}{l}\text { 减 少 } 8 \% \text { } 99 \% \text { 雨 } \\
\text { 水径流排人混合 } \\
\text { 污水设施 }\end{array}$ \\
\hline & & $\begin{array}{l}\text { 街道清扫扩展项目 } \\
\text { (Street Sweeping } \\
\text { Expansion) }\end{array}$ & $\begin{array}{l}\text { 增加干道清扫频次、清 } \\
\text { 扫时段和清扫路线 }\end{array}$ & $\begin{array}{l}\text { 减少雨水径流中 } \\
40 \% \text { 污染物, 成 } \\
\text { 本效益高 }\end{array}$ \\
\hline & \multirow{2}{*}{$\begin{array}{l}\text { 修复 } \\
\text { 植被 } \\
\text { 及水 } \\
\text { 生栖 } \\
\text { 息地 }\end{array}$} & $\begin{array}{l}\text { 城市森林项目 } \\
\text { (Trees for Seattle) }\end{array}$ & $\begin{array}{l}\text { 志愿者参与修复、维护 } \\
\text { 公园林地等; 鼓励居民 } \\
\text { 在自家庭院、邻近街道 } \\
\text { 种树 }\end{array}$ & - \\
\hline $\begin{array}{l}\text { 河段 } \\
\text { 尺度 }\end{array}$ & & $\begin{array}{l}\text { 河道栖息地修复 } \\
\text { 项目 }\end{array}$ & $\begin{array}{l}\text { 恢复河岸本土植被; 移 } \\
\text { 除鲑鱼洄游障碍 ; 改善 } \\
\text { 河道内栖息地等 }\end{array}$ & - \\
\hline
\end{tabular}

注：该框架包含一项河段尺度的修复项目；“一”表示该项目实施效果 暂不可得。

资料来源 : 作者根据参考文献 [25] 整理 
Duwamish River Habitat Restoration Plan)。该计划提出了潜在 的河口栖息地修复机会, 以及修复与河道商业、工业功能的 协同框架；并提出了修复栖息地类型及形态的建议，以指导 未来修复设计和实施 ${ }^{[29]}$ 。

\subsection{2 城市溪流重现}

(1) 拉文纳溪重现项目（Ravenna Creek Daylighting Project)

拉文纳溪位于华盛顿大学 (University of Washington) 北部的高密度住宅区, 与大学商业中心 (University Village) 邻接。该溪流现仅存 $1 \mathrm{~km}$ 于拉文纳公园（Ravenna Park） 内, 并完全由泉水供给, 不承担雨水排水功能, 是以茂林山 谷为特征的自然景观溪流 (图 5a)。历史上拉文纳溪由绿湖 (Green Lake) 流经 $4 \mathrm{~km}$ 进人华盛顿湖 (Lake Washington), 但在 1910 年代因绿湖水位降低而失去水源, 至今大部分已 被遮盖填埋, 并自 1940 年代被转接人城市混合污水系统而 与华盛顿湖断开连接。其流域面积由原来的 $23 \mathrm{~km}^{2}$ 缩小到 原来的 $1 / 20^{[30]}$ 。

拉文纳溪重现是社区居民在 1991 年借助合流制溢流削 减项目的机会提出的, 并经过长达 15 年的讨论和协商才得 以部分实施, 被认为是美国 “有最多研究的重现项目之一”。 污水处理厂原计划改线地下管道, 将干净的溪水分离并重 新排人华盛顿湖; 而社区的愿景是修复流域的过程和整体 性, 即在地表重新连接拉文纳溪和华盛顿湖, 让鲑鱼洄游并 栖息。为此, 社区组织拉文纳溪联盟 (RCA: Ravenna Creek Alliance）与业界、学界合作, 先后提出两个溪流路线情境 (约 $1.2 \mathrm{~km}$ ), 分别为穿越商业中心和沿公路边, 但均未与 商业中心和西雅图市达成协议 ${ }^{[31]}$ 。
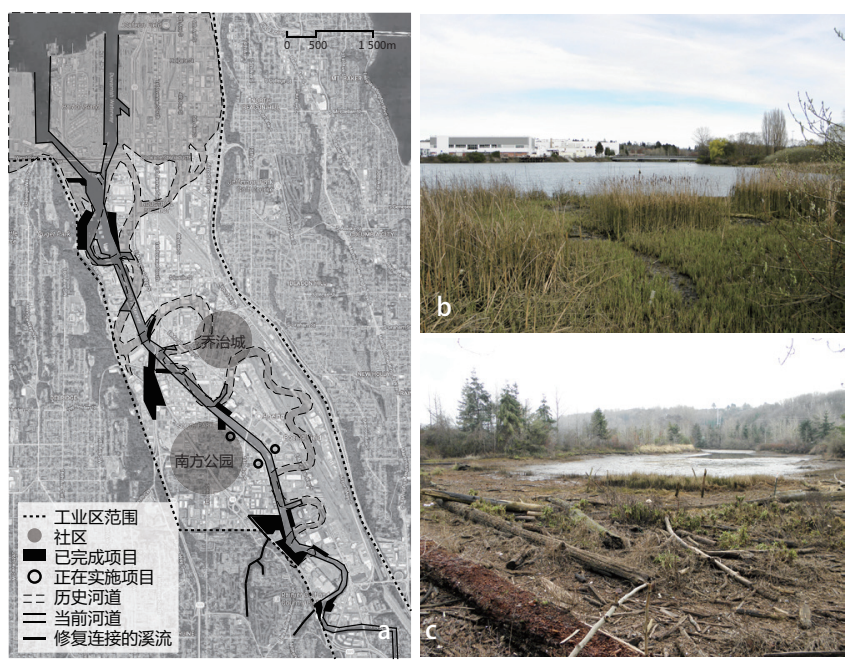

图 4 杜瓦米许河下游栖息地修复项目分布 ( a ) 及修复后场地 (b、c 资料来源 : $a$ 为作者绘制, $b 、 c$ 为作者拍摄
重现项目最终仅限于公园内, $200 \mathrm{~m}$ 溪流取代地下排水 管道而重返地表, 而后通过新的管道回归原先的受纳水体华 盛顿湖（图 5b,5c）。修复设计模仿了区域内一段自然溪流的 特征, 包括构建自然地形、河岸植被和河道内栖息地等（图 $5 \mathrm{~d})$ 。项目虽然没有实现预期的生态和地表连接, 但相比于 灰色基础设施, RCA 主席奥尼尔 ( $\mathrm{O}^{\prime} \mathrm{Neill}^{\prime}$ ) 认为溪流重现 是 “一个美好且有生态意义的事情”。

(2) 桑顿溪水质处理渠 (TCWQC: Thornton Creek Water Quality Channel) 项目

TCWQC 项目位于西雅图东北部的北门大型购物中心 (Northgate Mall), 并靠近桑顿溪南叉的源头。在北门社区 的驱动下, 项目重现了掩埋在一个 $3.6 \mathrm{hm}^{2}$ 废弃停车场下的 $550 \mathrm{~m}$ 的溪流, 使其成为上游城市雨水的汇水终端和下游桑 顿溪的水源地（图 6a）。不同于拉文纳项目单纯的溪流重现, TCWQC 项目将溪流重现与城市功能结合, 同时实现了雨水 水质处理、商业住宅开发和公共开放空间, 并成为复兴北门 城市中心战略计划的一部分。在局限的场地实现多种目标, 是该项目最大的挑战（图 6b,6c） ${ }^{[32]}$ 。

西雅图公共事业局将溪流重现扩展为一个绿色雨水设 施, 发展了西雅图雨水管理的新方法, 不仅实现河段自身 的修复, 而且也承担流域修复的功能。TCWQC 是雨水径 流在排人下游桑顿溪源头之前的水质处理渠, 其使用生物 滞留的原则管理 $91 \%$ 的由 $2.8 \mathrm{~km}^{2}$ 城市用地产生的雨水径流。 水渠的设计要素主要包括 ${ }^{[33]}$ :（1）基流河道、生物滞留阶 地和一系列沉淀池, 以最大化雨水径流处理的总量, 并移 除 40\% $80 \%$ 的沉淀物和污染物等; (2) 特殊选择的本土植 物类型, 使其在出现快速大量的水流时保持韧性, 降低水 流速度、延长滞留时间（图 6d)。同时, 项目保留了原来的
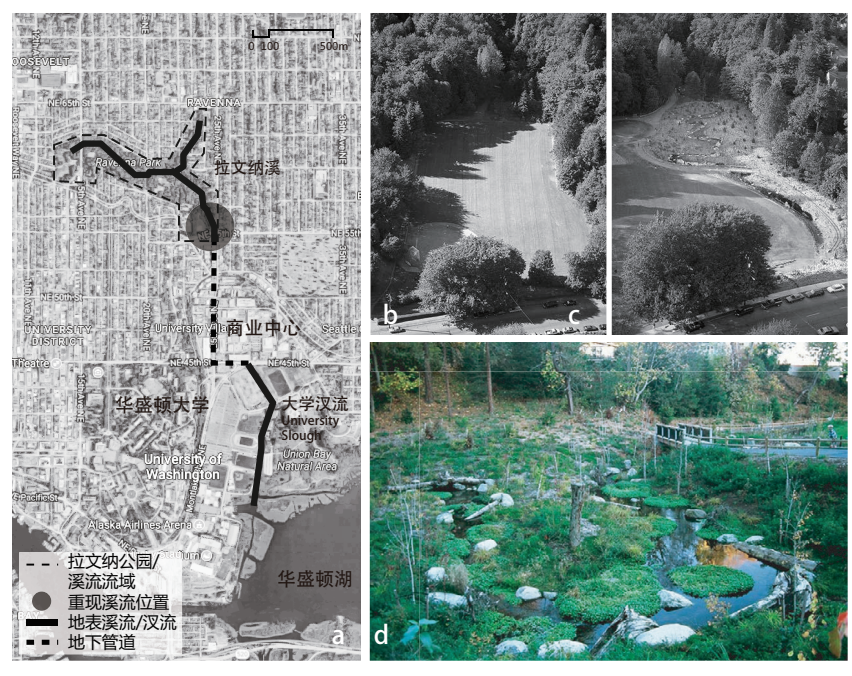

图 5 拉文纳溪重现项目 ( a ) 及修复前 (b) 后 (c、d) 资料来源： a 为作者绘制， b、c 来自 Andrew Buchanan， $d$ 来自 http://www.gaynorinc.com 
地下雨水管, 保证径流量在超过水渠容纳能力时可直排人 下游溪流。

重现和修复桑顿溪不仅改善了下游鲑鱼栖息地、降低雨 水径流对河道的影响, 而且复兴并提升了北部城市中心。这 个项目为北门增加了 $50 \%$ 的公共开放空间, 将社区到商业 中心的人行路径缩短了 $50 \%$, 减少场地不透水表面 $22 \%$, 并 且创造了新的鸟类及其他生物栖息地 ${ }^{[34]}$ 。

\section{3 河道修复的社会参与}

\subsection{1 自下而上的社区驱动}

社区居民和组织在西雅图河道修复中起到关键的驱动作 用, 包括项目建议、规划设计、利益协调、建设实施和建后 维护等过程。在这个过程中, 社区帮助塑造、维系修复项目, 同时修复项目也促进社区自身建设与复兴, 并与河道甚至流 域建立连接。

驱动力主要来自于生态和文化两个层面。一是公众对城 市河道的认知和态度发生了转变, 重新审视和欣赏其作为生 态系统所提供的多元价值。重现掩埋的溪流, 是这一转变产 生的最激进的实践 ${ }^{[35]}$ 。在拉文纳溪和桑顿溪项目中, 重现的 提议均是由社区决定提出, 并推动相关部门接受。社区也帮 助拓展修复的价值和目标, 以支撑长期实践。杜瓦米许河道 修复最初是单一部门主导的生态补偿, 但社区认为修复应是 一个为河道注人更多价值的过程, 进而促成了“城市工业经 济和自然系统的可持续共存” 的目标。二是社区愿意重建与 河道的文化和情感连接。鲑鱼是西雅图及西北太平洋地区重 要的文化象征, 社区因保护鲑鱼栖息地、使鲑鱼重返的共识 而支持河道修复。杜瓦米许河裁弯取直使曾经被弯道包围的 乔治城 (George Town) 和南方公园 (South Park) 两个社区 在空间上疏远河道, 这些社区通过自发参与修复及维护, 重 建与河道的联系 ${ }^{[36]}$ (图 4a)。

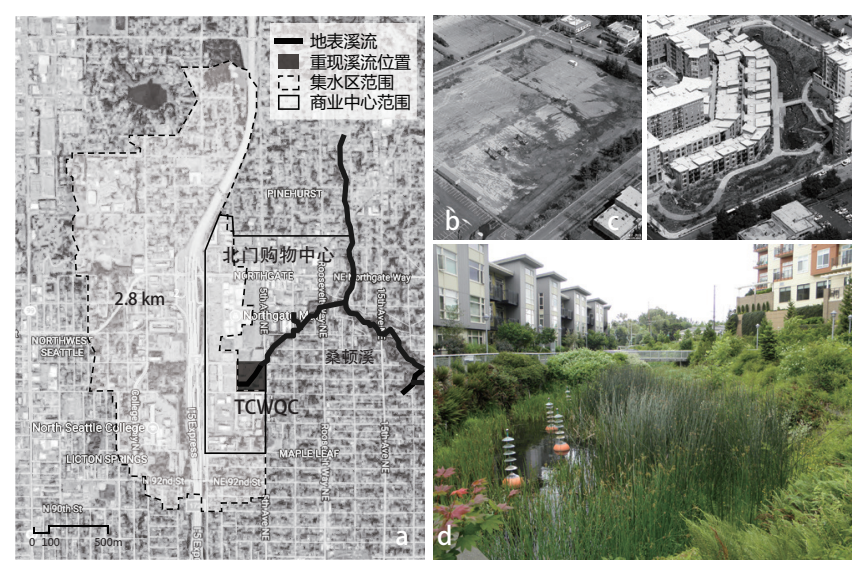

图 $6 \mathrm{TCWQC}$ 项目 $(\mathrm{a})$ 及修复前 $(\mathrm{b})$ 和修复后 (c、d)

资料来源 : $\mathrm{a}$ 为作者绘制， b、c 引自 https://landscapeperformance.org, $\mathrm{d}$ 为作者拍摄

\subsection{2 多利益群体协作}

修复项目在多种利益群体的参与和协作过程中逐渐推进 并优化, 这个过程促使不同利益群体达成一致, 并制定可行、 可实施的最优解决方案。满足相关利益群体的需求, 是评价 修复成功的标准之一。由于不同群体的利益需求各不相同, 同时某些群体在目标设定或实施策略的决策中具有更大影响 力, 因而协作过程具有一定弹性和不确定性 ${ }^{[15]}$ 。拉文纳溪项 目综合考虑了社区组织重现溪流、政府财政预算以及开发商 发展大型购物中心的需求, 最终重现了公园内一小段河道, 是各群体尊重彼此利益的结果。相比之下, 桑顿溪项目的协 作过程中, 一些利益群体起到了主导作用, 溪流重现的社区 提议因得到了有力的政治支持，而说服了其他群体也较快达 成一致, 并且西雅图公共事业局也借此提议进一步将水质处 理扩展纳人修复目标 ${ }^{[31]}$ 。

\section{3 总结与讨论}

我国对河道生态修复的关注起步较晚, 仅有 20 多年的 研究和实践历史, 尚未形成系统的理论和方法。很多经济较 发达的城市在河道整治工程中使用一些生态技术（如生态河 堤、河床和人工湿地等) 提升城市滨水景观, 但其生态效果

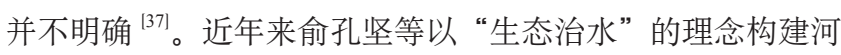
道生态廊道、沿河公园等, 恢复河道的生态过程并构建韧性, 为我国提供了新的治河理念和实践范例。本文研究发现, 城 市河道修复有助于促进河道生态、建成环境及社会环境之间 相互适应、结为整体, 并为城市河道管理和相关土地利用提 供一种可持续的方法。以下几个方面对我国实施城市河道修 复及“城市双修”具有重要借鉴意义。

（1）建立河道修复的流域观念。强调导致城市河道退化 的主要根源即流域城市化, 忽略流域影响、仅关注河道自身 的修复通常难以实现有效的生态提升。城市河道修复应将流 域和河段两个尺度的实践相结合, 通过流域内雨水管理、污 染控制等措施实现长期目标, 并通过河道自身的修复获得短 期效果。在实施河段修复前对流域状况进行评价, 帮助确定 合理的修复目标和方法。

（2）实施策略型修复和创新设计。在建成环境约束下, 小尺度、局部渐进是城市河道修复的普遍特征。通过实施策 略型修复, 独立项目不限于局部尺度, 而是在更大的景观尺 度上进行规划设计, 使修复构成城市绿色网络的潜在连接, 实现修复的积累效益。此外, 通过强调创新的政策制定和修 复设计, 推进河道修复有效实施, 在受限的条件下最大化河 道的生态系统服务, 促进多种功能、多元价值的空间叠加。

（3）协同河道修复与社区复兴、城市更新和开发。河道 修复通过促进公众参与, 增加新的公共开放空间, 重建居民 
与自然河道的联系, 帮助社区建设和复兴。同时, 城市更新 和开发也为河道修复提供机会 : 一方面, 将河道修复纳人临 近城市项目, 实现二者的整体设计与实施; 另一方面, 在流 域范围内的城市项目实施低影响开发, 减缓雨水径流对河道 的影响。

（4）考虑将绿色基础设施的方法作为“城市双修”的重 要策略。绿色基础设施的多功能性、适应性及其整合生态与 建成环境、社会经济的能力, 有助于转变传统的城市发展方 式, 并使在城市中恢复生态过程具备可行性。通过修复水系、 山体、废弃地以及完善绿地、推进海绵城市建设, 构建我国 城市的绿色基础设施网络, 并将其整合人城市肌理, 带动周 边发展, 提升城市整体弹性和可持续性。UP

\section{参考文献}

[1] PAUL M J, MEYER J L. Streams in the urban landscape[J]. Annual Review of Ecology, Evolution, and Systematics, 2003, 32(1): 207-231.

[2] VÖRÖSMARTY C J, MCINTYRE P B, GESSNER M O, et al. Global threats to human water security and river biodiversity[J]. Nature, 2010, 467(7315): 555-561.

[3] WALsh C J, ROY A H, Feminella J W, et al. The urban stream syndrome: current knowledge and the search for a cure[J]. Journal of the North American Benthological Society, 2005, 24(3): 706-723.

[4] SABBION P. Urban river restoration[M] // PERINI K, SABBION P. Urban sustainability and river restoration: green and blue infrastructure. Wiley Blackwell, 2016: 76-92.

[5] SABBION P. Green and blue infrastructure in cities[M] // PERINI K, SABBION P. Urban sustainability and river restoration: green and blue infrastructure. Wiley Blackwell, 2016: 1-9.

[6] BENEDICT MA, MCMAHON E T. Green infrastructure: smart conservation for the 21st century[J]. Renewable Resources Journal, 2002, 20(3): $12-17$

[7] The Nature Conservancy. China's Urban Water Blueprint[R]. Beijing: The Nature Conseruancy, 2016.

[8] SHOREDITS A S, CLAYTON J A. Assessing the practice and challenges of stream restoration in urbanized environments of the USA[J]. Geography Compass, 2013, 7(5): 358-372.

[9] CLEWELL A, ARONSON J, WINTERHALDER K. The SER international primer on ecological restoration[J]. Ecological Restoration, 2004, 2: 206-207.

[10] CLEWELl A F, ARONSON J. The SER primer and climate change[J]. Ecological Management and Restoration, 2013, 14(3): 182-186.

[11] National Research Council. Restoration of aquatic ecosystems: science, technology, and public policy[M]. Washington, DC: National Academy Press. 1992.

[12] PALMER M A, HONDULA K L, KOCH B J, et al. Ecological restoration of streams and rivers: shifting strategies and shifting goals[J]. Annual Review of Ecology, Evolution, and Systematics, 2014, 45(1): 247-269.

[13] COCKERILL K, ANDERSON W P. Creating false images: stream restoration in an urban setting[J]. Journal of the American Water Resources Association, 2014, 50(2): 468-482.

[14] PAlmer M A, FILOSO S, FANELli R M, et al. From ecosystems to ecosystem services: stream restoration as ecological engineering[J]. Ecological Engineering, 2014, 65(4): 62-70.

[15] KONDOLF G M, YANG CN. Planning river restoration projects: social and cultural dimensions[M] // DARBY S E, SEAR D A. River restoration: managing the uncertainty in restoring physical habitat. Wiley, 2008: 43-60.
[16] SIMENSTAD C A, TANNER C D, CRANDELL C, et al. Challenges of habitat restoration in a heavily urbanized estuary: evaluating the investment[J]. Journal of Coastal Research, 2005, 21(3): 6-23.

[17] EVERARD M, MOGGRIDGE H L. Rediscovering the value of urban rivers[J]. Urban Ecosystems, 2012, 15(2): 293-314.

[18] EDEN S, TUNSTALL S M, TAPSELl S M, et al. Translating nature: river restoration as nature - culture[J]. Environment and Planning D-society \& Space, 2000, 18(2): 257-273.

[19] PALmer M A, BERnHARdT E S, ALlan J D, et al. Standards for ecologically successful river restoration[J]. Journal of Applied Ecology, 2005, 42(2): 208-217.

[20] WALSH C J, FLETCHER T D, LADSON A R. Stream restoration in urban catchments through redesigning stormwater systems: looking to the catchment to save the stream[J]. Journal of the North American Benthological Society, 2005, 24(3): 690-705.

[21] MUSACCHIO L R. Urban ecology: science of cities[]]. Landscape Journal, 2015, 34(2): 193-194.

[22] ROSGEN D L. Natural channel design: fundamental concepts, assumptions, and methods[]]. Stream Restoration in Dynamic Fluvial Systems, 2011, 194: 69-93.

[23] Restore Our Waters[EB/OL]. [2017-06-25]. http://www.seattle.gov/util/ RestoreOurWaters/.

[24] SPU Proposes Integrated Plan to Protect Seattle Waterways[EB/OL]. [2017. 06-25] http://stormwater.wef.org/2015/06/spu-proposes-integrated-planprotect-seattle-waterways/.

[25] Seattle Public Utilities. Protect Our Waters[EB/OL]. [2017-06-25]. http:// www.seattle.gov/util/EnvironmentConservation/OurWatersheds/ ProtectOurWaters/index.htm.

[26] 700 Million Gallons[EB/OL]. [2017-06-25]. http://www.700milliongallons.org/.

[27] King County. Our Duwamish[EB/OL]. [2017-06-27]. http://www.kingcounty. gov/services/environment/watersheds/green-river/OurDuwamish.aspx.

[28] SIMENSTAD C A, TANNER C D, CRANDELL C, et al. Challenges of habitat restoration in a heavily urbanized estuary: evaluating the investment[]]. Journal of Coastal Research, 2005, 21(3): 6-23.

[29] Seaport Planning Group. Lower Duwamish River Habitat Restoration Plan[R]. 2009.

[30] YOCOM K. Building watershed narratives: an approach for broadening the scope of success in urban stream restoration[J]. Landscape Research, 2014, 39(6): 698-714.

[31] O'NEILL K, GAYNOR P. Retrieving buried creeks in Seattle political and institutional barriers to urban daylighting projects[M] // FRANCE R L. Handbook of regenerative landscape design. CRC Press, 2008: 73-107.

[32] GIRALDO G, LO M, DAVIES M, et al. Thornton creek water quality channel, urban water quality, and environmental benefits[M] // Low impact development: new and continuing applications. Reston Va American Society of Civil Engineers, 2009: 220-225.

[33] GIRALDO G, DAVIES M, PREISLER S. Thornton creek water quality channel: from parking lot to channel headwaters[M] // Low impact development 2010: redefining water in the city. American Society of Civil Engineers, 2010: 1709-1720.

[34] Thornton Creek Water Quality Channel: Methodology for landscape performance benefits[EB/OL]. [2017-06-30]. https://lafoundation.org/ myos/my-uploads/2010/09/03/svrtcwqcmethodology.pdf.

[35] PINKHAM R. Daylighting: new life for buried streams[M]. Rocky Mountain Institute, 2000.

[36] CORMIER N S. Growing Green Infrastructure Along the Urban River Duwamish Stories[M] // FRANCE R L. Handbook of regenerative landscape design. CRC Press, 2007.

[37] 高晓琴, 姜姜, 张金池. 生态河道研究进展及发展趋势 [J]. 南京林业大 学学报 (自然科学版), 2008(1): 103-106.

(本文编辑：秦潇雨) 